\title{
I niciação sexual, masculinidade e saúde: narrativas de homens jovens universitários
}

\author{
Sexual initiation, masculinity and health: narratives of young men
}

Lúcia Emilia Figueiredo deSousa Rebello ${ }^{1}$

Romeu Gomes ${ }^{1}$

${ }^{1}$ Instituto Fernandes Figueira, Fiocruz. Av. Rui Barbosa 716, Flamengo. 22250-020 Rio de Janeiro RJ. le-rebello@uol.com.br
Abstract The main objective of this study was to analyze the narratives of young university students about the experience of sexual initiation. The theoretical and conceptual references used were the sexual scripts of our society that inform people about when, how, where and with whom they should have their sexual experiences, indicating how to act sexually and the reasons why they haveto practice some kind of sexual activity. The method used was a qualitative study of narratives from the perspective of dialectic hermeneutics. The methodological design involves the comprehension of sceneries, contexts, environments and characters of the narratives about sexual initiation. The analysis refers to narratives of university students in the city of Rio de Janeiro. Among the meanings of sexual initiation, we emphasize sexual intercourse, the demarcation of a stage of life, the awakening to the opposite sex and the discovery of the body. We observed that the young men's narratives were coherent with what is considered masculine, present in the discourse of different generations. It is concluded that the young men should be encouraged to participate in actions combining health and education aimed at promotion of sexual and reproductive health.

Key words Sexuality, Gender identity, Youth, $\mathrm{H}$ ealth and narrative
Resumo 0 objetivo do trabal ho éanalisar narrativas de homens jovens universitários sobre a experiência de iniciação sexual. 0 referencial teórico-conceitual foi o de scripts ou roteiros sexuais que se caracterizam como aprendizados sociais que informam os sujeitos sobre quando, como, onde e com quem devem ter experiências sexuais, indicando como agir sexualmente eas razões pelas quais devem ter algum tipo deatividadesexual. 0 método da investigação se configura como um estudo de narrativas, ancorado na abordagem de pesquisa qualitativa a partir da perspectiva hermenêutica dialética. 0 desenho metodológico envolve a compreensão de contextos, cenários, enredos e personagens das narrativas acerca da iniciação sexual. A análise se refere a narrativas de universitários na cidade do Rio de Janeiro. Dentre os significados da iniciação sexual, destacam-se os de coito, demarcação de uma etapa da vida, despertar para o gênero oposto e descoberta do corpo. O bserva-se, ainda, como resultado do estudo, que as narrativas dos jovens foram coerentes com um modo de ser homem quese faz presente no discurso de diferentes geraç̧ões. Concluiu-se que épreciso um trabaIho conjunto em saúde e educação que privilegie o protagonismo dos homens jovens em ações com vistas à promoção de saúde sexual e reprodutiva.

Palavras-chave Sexualidade, Identidadedegênero, Juventude, Saúde e narrativa 
Introdução

0 início da vida sexual é considerado, historicamente, como um dos importantes marcos da passagem da infância para a vida adulta ${ }^{1-6}$. Este início, tanto no senso comum como no meio acadêmico, tem sido associado à primeira relação sexual com penetração (coito) entre pessoas de sexos oposto $^{6-8}$. Alguns autores, entretanto, ampliam este conceito para todo o processo de experimentação física e relacional queseinicia nas primeiras manifestações da puberdade e se estende até depois da primeira relação sexual $3,4,9,10$.

Ainda que os conceitos de iniciação sexual, citados anteriormente, possam servir como ponto de partida, identificar etrabalhar com os significadosqueos sujeitos atribuem à experiência deiniciação sexual nos permite uma análise que reflete tanto aspectos subjetivos como questões socioculturais. É neste sentido que compreender os scripts sexuais que permeiam a conduta dos homens jovens torna-se fundamental ${ }^{3,11,12}$. Entretanto, nem sempre nos é possível ter acesso a essa compreensão, isto porque, para o universo masculino, falar de si e de suas incertezas pode ser entendido como fraqueza ou ausência de masculinidade ${ }^{13} \mathrm{e}$, assim, mesmo queo jovem do século XXI seja visto como livre e bem informado, quando 0 assunto é sexo há muitas dúvidas e conflitos a serem desvelados.

Em termos de idade da primeira relação se xual, Borges e Schor ${ }^{8}$, com base numa ampla revisão da literatura, apontam "que o início da vida sexual dehomens ocorrebasicamente ao redor dos 15 anos de idade". As pesquisas indicam que, entre rapazes e moças, a idade em que ocorre a primeira relação sexual vem diminuindo ea atividade sexual, aumentando $\mathrm{o}^{14,15}$. No entanto, ainda persisteuma dupla moral sexual, determinando normas e expectativas sociais em relação à idade e circunstâncias adequadas para as primeiras práticas sexuais, que diferenciam homens e mulheres ${ }^{16,17}$.

São os scripts sexuais, decorrentes de aprendizados sociais, que informam aos sujeitos sobre quando, como, ondee com quem devem ter experiências sexuais. Indicam, ainda, como agir sexualmente eas razões pelas quais devem ter al gum tipo de atividade sexual ${ }^{12,18}$. Estes scripts são menos resultantes do ditame de normas, regras e interdições, do que da impregnação por narrações envolvendo seqüências de acontecimentos ou, ainda, da interiorização dos modos de funcionamento das instituições ${ }^{12,19,20 .}$

De um modo geral, há uma tendência a se depreciar as afirmações explicativas dadas pelas pessoas sobre seu comportamento, o que, de certo modo, pode explicar que só recentemente os estudos voltados para a consideração dos próprios jovens e suas experiências, suas percepções, formas de sociabilidade e atuação, venham ganhando vulto ${ }^{5,12}$.

M esmo que se reconheça a importância de envolver os homens jovens nas intervenções de prevenção e promoção de saúde sexual, há pouca informação sobre o que estes homens jovens pensam sobre sua própria sexualidade $e^{21,22}$.

As descrições e reflexões oferecidas pelas narrativas dos sujeitos deste estudo devem ser entendidas como relatos socialmente produzidos e culturalmente situados. Caminhando nessa compreensão, buscamos discutir a especificidade da sexualidade dos homens para além de seu papel instrumental, no sentido de contribuir para que estes sejam vistos também como protagonistas das ações da saúde sexual e reprodutiva, numa perspectiva relacional de gênero. Com isto, não estamos apenas caminhando no avanço da discussão acerca da sexualidade masculina, mas também na direção das implicações desta no campo da saúde sexual feminina ${ }^{23}$.

A partir destas considerações, o objetivo do nosso artigo é analisar as narrativas de homens jovens universitários, sobrea experiência deiniciação sexual, buscando identificar uma possível interface entre iniciação sexual, identidade masculina e saúde.

\section{Método}

A pesquisa pautou-se numa abordagem qualitativa, entendida como um conjunto de práticas interpretativas que busca investigar os sentidos que os sujeitos atribuem aos fenômenos eao conjunto de relações em que eles se inserem ${ }^{24}$. N esta abordagem, com baseem princípios da hermenêutica-dialética ${ }^{25}$, buscamos caminhar na compreen são e na contextualização dos sentidos subjacentes às narrativas dos sujeitos investigados.

N este desenho de estudo, entendemos a narrativa como uma forma de representar e recontar a experiência, sendo os eventos apresentados em uma ordem significativa e coerente para o narrador, permitindo que este possa perceber uma articulação entre presente, passado e o futuro ${ }^{11}$.

Utilizamos as regras desta técnica de entrevista para ativarmos o esquema da história; provocarmos narrações dos informantes e, uma vez começada a narrativa, conservarmos a narração através da mobilização do esquema autogerador ${ }^{26}$. Houve certo questionamento, por parte dos sujeitos da 
pesquisa, à narrativa como forma de entrevista, sendo apontado que seria mais fácil setivessem que responder a um questionário ou a perguntas sobre o tema. N estesentido, apóstermos explicado o contexto da investigação e obtermos sua permissão para gravar, formulamos o tópico inicial para a narração sobre a experiência de iniciação sexual. Iniciada a narração, esta não foi interrompida até que houvesse uma clara indicação de que o entrevistado havia terminado a narrativa. N estemomento, perguntamos ao informante se ele desejava acrescentar mais algum detal he à sua narrativa. 0 tempo médio de narração até o seu fim "natural" foi de vinte minutos. Passamos, então, à fase de questionamentos. As questões, que foram formuladas com base no interesse de nossa pesquisa, foram traduzidas em temas, tópicose relatos deacontecimentos que surgiram durante a narração, empregando-se a linguagem do informante, na tentativa de completar as lacunas existentes da história. Ao final da entrevista, com o gravador desligado, em alguns casos, surgiram discussões interessantes na forma decomentários informais relevantes para a interpretação da narração no seu contexto. No sentido de não perder esta informação, utilizamos o recurso do diário de campo.

Cabe ressaltar que, em função da especificidade do tema da pesquisa, o local onde foram realizadas as entrevistas narrativas foi indicado pelos próprios entrevistados. Ainda que dois jovens tenham indicado as próprias residências justificando que ficariam mais à vontade para falar em função da privacidade, a maioria dos informantes preferiu ser entrevistado na própria universidade, em horários próximos às aulas.

A amostra do estudo foi composta a partir dos seguintes critérios recomendados por M inayo ${ }^{25}$ : (a) escolher os sujeitos que detinham os atributos relacionados ao estudo; (b) considerar tais sujeitos em número suficiente para que se pudéssemos ter uma certa reincidência das informações; (c) considerar a possibilidade de inclusões sucessivas de sujeitos até que fosse possível uma discussão densa das questões da pesquisa. Com isto, não buscamos uma representatividade numérica e sim um aprofundamento da temática.

$\mathrm{Na}$ sel eção dos sujeitos, adotamos uma prática bastante usual em pesquisa sobre os universos familiares, em que pessoas conhecidas do pesquisador indicaram outras a serem entrevistadas, que, por sua vez, indicaram outras conhecidas ${ }^{27}$. Em termos de critérios deinclusão dos homens jovens, procuramos fazer contato com universitários. Este critério incluiu os entrevistados em um grupo que tem acesso à informação, permitindo problemati- zar o pressuposto de que tal acesso transforma de imediato as práticas sexuais juvenis 4 . Possibilitou, ainda, que os autores das narrativas apresentassem uma visão mais reflexiva em relação à própria experiência de iniciação sexual. Um outro critério foi o de que os sujeitos pertencessem a uma mesma geração, isto é, um grupo de pessoas que, por ter nascido numa determinada época, experimentou acontecimentos sociais comuns ${ }^{27}$. N este sentido, selecionamos homens jovens nascidos na dé cada de 80 do século passado, quetiveram sua iniciação sexual nos anos noventa desse mesmo sécuIo. A escolha deste período se situa num contexto de mudanças sociais significativas, como a exemplo da emergência da epidemia da aids nos anos 1980 e do novo olhar sobre a saúde sexual e reprodutiva como um direito.

M esmo trabalhando com universos familiares na seleção dos sujeitos, o fato da pesquisadora ser uma mulher edeuma geração diferente da geração dos sujeitos do estudo, em alguns momentos, interferiu na decisão destes em aceitar ou não participar da pesquisa. Nesta perspectiva, para que pudéssemos ter acesso a alguns dos jovens e as suas narrativas, tornou-se necessário inserir, como auxiliar de pesquisa, um homem da mesma geração dos entrevistados.

Em termos de seqüência metodológica, seguimos a proposta de Gomes e M endonça ${ }^{11}$ para uma análise dos aspectos estruturais da narrativa. Numa primeira etapa, buscamos compreender o contexto das representações e da experiência de iniciação sexual. Esta compreensão não consistiu num momento específico do processo de interpretação. Assim, inicialmenterealizamos um breveestudo do contexto histórico e sociocultural da sexualidade em relação àsprimeiras experiências sexuais masculinas, que foi sendo ampliado com base nas narrativas.

$\mathrm{Na}$ segunda etapa, procuramos desvendar os aspectos estruturais da narrativa - os significados atribuídos à iniciação sexual, os cenários das narrativas da experiência de iniciação sexual, os personagens e espaços evocados, eventos mencionados para se contar como aconteceu, 0 enredo e 0 desfecho delineado pelos narradores.

Como terceira etapa, elaboramos uma síntese interpretativa, em que os dados revelados pelas narrativas dial ogaram com o contexto sócio-histórico.

Os sujeitos do estudo só foram abordados após termos obtido aprovação do Comitê de Ética em Pesquisa do Instituto Fernandes Figueira da Fundação Oswaldo Cruz e, na apresentação dos dados, utilizamos nomes fictícios para que o princípio do anonimato fosse garantido. 


\section{Autores das narrativas eo cenário social}

0 grupo de autores das narrativas se constituiu inicialmente de dez homens jovens. No entanto, durante a narrativa, verificamos que um dos jovens não atendia ao critério de inclusão que determinava que 0 entrevistado/informante tivesse vivenciado, segundo seus próprios parâmetros, uma experiência de iniciação sexual. No entendimento deste jovem, a iniciação sexual corresponde à primeira relação sexual com penetração vaginal, experiência não vivenciada por ele. Sendo assim, 0 grupo que teve suas narrativas analisadas foi formado por nove homens jovens, universitários, se xualmente ativos.

Além de terem nascido na cidade do Rio de Janeiro, os autores das narrativas afirmaram residir, desde o nascimento, em bairros da zona norte (5), zona oeste (2) e zona suburbana (1), com exceção de um que, tendo nascido na zona norte, na época do trabalho de campo, residia na baixada fluminense (1). 0 conjunto dos locais de moradia confere aos entrevistados uma identidade sociocultural urbana.

Como ponto de partida para uma contextualização do cenário da iniciação sexual destes jovens, consideramos o pertencimento a uma mesma ge ração ${ }^{27,28}$, ou seja, a geração da década de 1980 , por terem nascido entre 1981 e 1987, sendo a mé dia de idade entre eles de 21 anos. Estes indicaram que a iniciação sexual ocorreu nos anos noventa. A idade apontada para a primeira relação sexual foi de catorze anos. Esta média de idade se encontra abaixo da média referida pela literatura ${ }^{14}$. A penas quatro declaram estar inseridos no mercado de trabalho. Nestas condições, todos ainda residiam com suas famílias de origem. Essas características revelam um perfil próprio da geração dos jovens dos anos oitenta, que vivem a indeterminação do mundo do trabalho e a fluidez do sentido de ser jovem, estejam eles emancipados ou não da família de origem ${ }^{29}$.

Quanto ao curso universitário, procuramos selecionar preferencialmente alunos do curso de engenharia que, segundo pesquisa da Fundação Getúlio Vargas ${ }^{30}$, é onde predominam os representantes do sexo masculino (96\%). Como contraponto e ainda com base na mesma pesquisa, selecionamos um aluno do curso de serviço social, no qual ocorre a predominância de representantes femininos (97\%).

O cenário das narrativas de iniciação sexual analisadas neste estudo se inscreve na década de 1990 que, segundo Fernández-Galiano ${ }^{31}$, poderia ser chamada de década global, posto que, com a extinção do mundo bipolar, o fenômeno da globalização acelerou-se prodigiosamente; década virtual, porque virtual é, com efeito, o inédito universo que se multiplicou nesses dez anos; década dócil, adjetivando o conformismo social eideológico de um planeta submetido a uma só potência e a um só pensamento. Mas que melhor se define como década digital, pois esse termo matemático e orgânico resume, à sua maneira, os outros três.

Ainda neste cenário, contabilizam-se os novos desafios diante da epidemia da aids. As campanhas oficiais de prevenção contra a aids, iniciadas ainda em 1987, adotavam, no início dos anos noventa, um discurso intimidatório eque reforçava a discriminação, em que a idéia central era: a aids não tem cura e mata. Este discurso enfrentou a resistência dos movimentos sociais organizados, àquela altura, engrossados pelas $0 \mathrm{~N} G$ s de pessoas soropositivas. Com o passar dos anos, torna-se consenso que faz parte da prevenção a luta contra discriminação e o preconceito ea defesa da solidariedade e dos direitos das pessoas vivendo com HIV/aids ${ }^{32}$.

A cidade do Rio de Janeiro torna-se palco para o Projeto Aids e a Escola, a partir do entendimento de que a escola era o lugar ideal para a difusão do conhecimento considerado necessário para a iniciação e vivência sexual dos joven $\mathrm{s}^{33}$. As relações entre família e sexualidade também vivenciam um processo de transformação, em que a conjugalidade torna-se um domínio relativamente autônomo da família e a atividade sexual deixa de ser restrita ao casamento ${ }^{3,17,34 .}$

Ainda que o Rio Janeiro seja considerado metrópole de vanguarda no que diz respeito à liberação de costumes ${ }^{16}$, persiste em grande parte das famílias dificuldades em lidar com a nova realidade que se impõe à sexualidade juvenil, tendo sido destacado por um dos sujeitos como um desafio a ser superado pelas próximas gerações:

Acho importante abordar a questão do preservativo. O sjovens estão transando cada vez mais cedo e talvez por medo de como os pais irão reagir se por acaso encontrarem na bolsa de uma menina de catorze anos uma camisinha, faz com que essa menina não ande ou não queira que seu parcei ro use preservativo. Também não acho simples para uma família achar com um rapaz de catorze/quinze anos uma camisinha. É evidente que pra mulher é muito pior. Talvez a próxima geração de pais tenham uma cabeça melhor para lidar com isso. Pelo menos eu que nasci nos anos oitenta, que cresci num tempo de aids, quer dizer, de inúmeras outras doenças sexualmente transmissíveis, mas a aids... Espero que eu como as pessoas de minha geração que cresceram 
nesse meio, quando se tornem pais, entendam a importância de saber lidar com isso para seus filhos. (André, 19 anos)

Os anos noventa foram, também, marcados por um crescente interesse das pesquisas no sentido de compreender melhor como homens jovens são socializados, do que necessitam em termos de um desenvolvimento saudável e dequeforma saúde e educação podem se unir para melhor atendê los em sua especificidade. 5 . Conferência I nternacional de População e Desenvolvimento no Cairo (1994) e a IV Conferência sobre Mulheres (1995), em Beijing, constituíram a fundamentação necessária à compreensão da importância de se incluir homens adultos e jovens nos esforços de melhor atendimento no campo da saúde sexual ${ }^{21,20}$.

\section{Significados atribuídos pelos sujeitos}

\section{à iniciação sexual}

Os autores das narrativas apresentaram diferentes significados para a iniciação sexual. De um modo geral, cada jovem apresentou mais de um significado. Entretanto, todos os significados têm como referência scripts sexuais envolvendo a perspectiva heterossexual. A penasum dossujeitos apresentou a iniciação numa perspectiva de interação sexual entre sujeitos do mesmo sexo.

0 primeiro significado apresentado para iniciação sexual é de demarcação de uma etapa da vida. Um marco detransição entrea infância evidaadulta, bem como de definição da própria identidade, o que para a maioria dos entrevistados corresponde à expectativa de "ser homem".

É toda uma série de fatores que começa desde quando o jovem deixa de ser uma criança, passa pela adolescência e começa a descobrir o que é o sexo e a definir a sua opção sexual. (Diogo, 20 anos)

Conversa com os amigos, masturbação, revistas eróticas essas coisas todas estão relacionadas à iniciação sexual. (H élio, 22 anos)

A iniciação sexual é uma das fases mais importantes da vida. É a fase em que o homem começa a descobrir que não é o único no mundo, é a perca da inocência e início da maturidade. (Bruno, 20 anos)

0 segundo significado é o de que a iniciação sexual é um despertar para o sexo oposto. Gagnon ${ }^{12}$ aponta que este despertar obedece a roteiros sociais de gênero, que são ensinados às crianças na mais tenra idade. Estes roteiros explicitam as formas apropriadas de iniciação, controle e dominação que devem existir entre meninos e meninas, mulheres e homens.

$\mathrm{Na}$ iniciação sexual, o cara começa a descobrir que existe um tipo de relacionamento diferente de amizade entre homem e mulher. (Ivan, 19 anos)

Vai desde a primeira conquista da primeira garota que geralmente é idealizada até o fato inicial que se sucede. (César, 22 anos)

Mesmo na narrativa do jovem que declarou "gostar de meninos", este despertar para o sexo oposto aparece como um roteiro de iniciação sexual a ser seguido equelimita por longo período a expressão de sua sexualidade no "sentido prático da coisa", como ele mesmo define:

Aos doze anos descobri que gostava de meninos, mas dos doze até os quase dezesseis anos eu não vivenciei no sentido prático da coisa porque eu achava que ia conter o meu desejo, achava que ia passar, queaquilo era só uma fasecomo todo mundo sempre diz. (Flavio, 25 anos)

0 terceiro significado é o de que a iniciação sexual é a descoberta, incluindo a descoberta do corpo como fonte de desejo e prazer.

Depois de um certo número de descobertas, de nos tocar, acariciar, essas coisas, a gente chegou ao ato sexual. Foi a primeira vez que eu vi um seio na minha frente, emulher mesmo. Eu tirei a blusa dela e eu vi o seio dela, fiquei meio espantado, na hora não sabia o que fazer. (Bruno, 20 anos)

Segundo Gagnon ${ }^{12}$, esta descoberta envolve roteiros de gênero que, na nossa cultura, apresentam o desempenho orgástico como uma forma rotineira de comportamento na maioria dos meninos, em conjunto com a masturbação no início da puberdade.

0 quarto significado é dequea iniciação sexual é penetração, significado este também presente em diferentes estudos sobre iniciação sexual5-8,35. Este significado apareceu na fala de todos os jovens, independente do gênero do parceiro.

Quando você é gay, talvez vocêperca a virgindade de duas maneiras diferentes. $N$ ão sei seisso éreal, nem dá pra dizer se do ponto de vista prático são duas experiências diferentes, mas do ponto de vista simbólico tem uma diferença em ser penetrado e ser o penetrador. Eu entendo que perdi minha virgindade duas vezes porque fiz duas coisas diferentes. (Flavio, 25 anos)

\section{Síntese interpretativa}

$N$ as narrativas dos sujeitos deste estudo, os scripts sexuais envolvendo a experiência de iniciação sexual encontram-se subordinados a scripts de "ser homem". Os jovens autores das narrativas apontaram medo e ansiedade de não corresponderem às expectativas de idade para a iniciação sexual. 
Ainda que os sujeitos deste estudo não tenham mencionado em suas narrativas uma forte pressão dos pares no sentido de precisar, a todo custo, ter a primeira relação sexual para se provar como homem, ficou claro que o medo de não corresponder às expectativas tem por trás uma pressão social pautada em padrões hegemônicos de masculinidade. Neste sentido, destacamos que a maioria dos sujeitos finalizou a narrativa da primeira relação sexual com frases afirmativas: "eeu gostei"," "eu achei bom", as quais um dos jovens ainda acrescentou "isso é óbvio", cabendo pensar em uma cobrança subjetiva - e se eu não gostar? Portanto, possivelmente, os homens jovens sentem a necessidade de provar para si mesmos, através de sua primeira relação sexual, que são "homens de verdade".

Também no campo da saúde, observamos que diferentes processos de socialização, reproduzidos a cada geração, estabelecem que o cuidado com a saúdeécaracterística da mulher, ou seja, não é próprio do masculino ${ }^{13,36-38}$. Sendo assim, é compreensível que nas narrativas dos nossos jovens não tenha aparecido a preocupação com o cuidado da própria saúde sexual. A exceção disso, identificamos na narrativa de um único jovem a informação de ter buscado ajuda de um urologista, sendo esta não no sentido deum cuidado preventivo, mas sim propiciada pelos sintomas de uma doença.

Há um consenso quanto à dificuldade em integrar o homem no processo de cuidado da própria saúdee da saúde da parceira, principalmentequando este cuidado passa pela problematização de de terminadas práticas masculinas validadas como "naturais". M esmo que a aids tenha propiciado que o uso do preservativo fizesse parte dos scripts sexuais e ainda que os jovens desteestudo tenham apre sentado um bom nível de informação neste sentido, as narrativas apontaram que, na maioria das vezes, estes não utilizam o preservativo nas relações sexuais que se sucedem à primeira relação sexual.

Uma primeira justificativa para este fato é que a maioria dos sujeitos das narrativas apresentou, como parceiras de iniciação sexual, as namoradas. O namoro, no discurso destes jovens, pressupõe uma relação de exclusi vidade entre pessoas que se gostam e, sendo assim, haveria uma confiança de que "nada de mal aconteceria" (André, 19 anos). Isso se reforça a partir de inúmeros estudos acerca da sexualidade masculina ${ }^{1,14,18,37}$.

Outras justificativas apontadas são 0 fato de "ter sido pego de surpresa" (Hélio, 22 anos e Bruno, 20 anos) e a dificuldade para colocar o preservativo: "eu erro o lado, gasto várias até colocar corretamente e acabo perdendo vários minutos preciosos" (Diogo, 20 anos). Neste sentido, fica claro o entendimento de sexo como performance, ou seja, que existe um roteiro sexual a ser seguido sem erros para que se consiga obter um "desempenho competente" ${ }^{12}$. Assim, muitos jovens, para garantir uma boa performance, preferem não correr o risco deperder a ereção, em meio à dificuldade para colocar o preservativo, e têm relações sexuais sem proteção.

0 processo de aprendizado e construção da identidade masculina faz parte de um cenário histórico-cultural que indica o queéuma sexualidade "normal", em relação a "ser homem". Ser homem é ser heterossexual, éser viril, éser penetrador, mesmo para quem, teoricamente, se diferencia deste padrão de "normalidade".

Fomos pro motel e, no auge de brincadeiras, beijos, sei lá, ele disse que era virgem, mas que queria que fosse comigo. Isso me deixou com uma aura de responsabilidade pelo fato de ser a primeira vez dele e ele querer ser penetrado por mim. Não vou mentir que isso não traz um certo tipo de sentimento diferente em você. É lógico que você projeta valores que a sociedade, sua família vão tedando, eesseéum dos valores que perpassam as relações familiares. Sexo entre homens não é diferente do sexo em geral. É diferente porque você tem que desconstruir na sua cabeça uma série de coisas que você acha que é errado, que é pecado, que não é normal. É fato que com ele não aconteceu porque nós já éramos namorados. (Flávio, 25 anos)

Ainda que não seja entendido como parte hegemônica ou "tradicional" da identidade masculina, o desejo de fazer coincidir a experiência sentimental ea experiência sexual pode ser identificado nas narrativas dos sujeitos deste estudo:

Conheci minha namorada eu tinha catorze anos e estou com ela até hoje. $N$ ão que não tenha rolado outras garotas entre nossas idas e vindas, mas é dela que gosto na boa. Para mim iniciação sexual ésentir tesão, é querer transar com uma garota e conseguir. Quando a gente se gosta é melhor. (Ivan, 19 anos)

U m grande problema queteria éque chegou num momento que se eu não ti vesse, por sorte, conseguido essa namoradinha, a primeira que chegasse aconteceria a minha primeira transa. (César, 22 anos)

Eu idealizava encontrar o grande amor da minha vida. Transar com ele, perder a virgindade com ele, e depois casar, viver junto para o resto da vida. (Flavio, 25 anos)

Através da análise das narrativas da experiência de iniciação sexual, tanto nos foi possível reproduzir aspectos de uma masculinidade hegemônica como atualizar este modelo. Esta ampliação do conhecimento sobre as primeiras experiências sexuais masculinas lançanovos conhecimentosque 
permitem uma melhor abordagem da sexualidade tanto para a saúde como para a educação.

\section{Consideraçõesfinais}

M esmo quea relação sexual com penetração tenha sido o significado mais presente nas narrativas, reforçando a idéia de que ser homem é ser penetrador, não podemos perder de vista que outros significados, como demarcação deuma etapa da vida, como despertar para o gênero oposto, como descoberta do corpo, também apontam comportamentos coerentes com um modo de ser homem que se faz presenteno discurso de diferentes gerações, seja no sentido de afirmação de uma identidade masculina, seja para indicar caminhos possíveis de transgressão.

Tendo como ponto de partida para a análise de práticas sexuais a compreensão dos roteiros de gênero, reforçamos a idéia de que a informação por si só não impede que o jovem assuma determinados tipos de comportamentos em suas relações sexuais. Em termos de idade em que ocorre a

\section{Colaboradores}

LEFS Rebello e R Gomes participaram igualmente de todas as etapas da elaboração do artigo. primeira relação sexual, percebemos que esta obedece a scripts de gênero e que os homens jovens se sentem pressionados, de algum modo, a provar sua masculinidade iniciando sua vida sexual cada vez mais cedo.

Neste sentido, reforçamos a importância de estratégias de promoção de saúde que incentivem a participação de homens jovens e que os encorajem a mostrarem os seus sentimentos, a falarem de suas dúvidas e frustrações, sem a intenção de criarmos modelos de controle e/ou de comportamentos normatizados ${ }^{39,40}$.

A partir desteprimeiro passo, que foi de escuta do queum grupo dehomens jovenstinham a dizer sobre sua sexualidade, visualizamos um horizonte de possibilidades no sentido de proposição de novas formas de abordagem sobre velhos conceitos que insistimos em reforçar. Seja como pais, educadores ou profissionais de saúde, acreditamos ter a certeza de que sabemos o que é bom para os jovens, o que eles precisam eo que eles desejam. Admitir que podemos aprender com eles e que não sabemos tudo sobre eles pode ser um caminho de mudança desta crença.

\section{Referências}

1. Pimenta C, Rios LF, Britto I, Terto Jr V, Parker R. Passagem segura para a vida adulta: oportunidades e barreiras para a saúde sexual dos jovens brasileiros. Rio de Janeiro: Associação Brasileira Interdisciplinar de Aids; 2001.

2. Rieth F. A Iniciação Sexual na Juventude de Mulheres e H omens. H orizontes Antropológicos 2002; 17(Supl 8):77-91.

3. Bozon M. Sociologia da sexualidade. Rio de Janeiro: FGV; 2004

4. Brandão ER. Iniciação sexual e afetiva: exercício da autonomia juvenil. In: Heilborn $M L$, organizadora. Família e sexualidade. Rio de Janeiro: FGV; 2004. p. 64-86.

5. Abramo HW. Considerações sobre a tematização social da juventude no Brasil. Rev Brasileira de Educação 1997; (Supl 5-6):25-36.

6. Borges ALV, Schor N. Início da vida sexual na adolescência e relações de gênero: um estudo transversal. Cad Saúde Pública 2005; 21(Supl 2):499-507.

7. Taquette SR, Vilhena M M, Paula MC. Doenças sexualmente transmissíveis e gênero: um estudo transversal com adolescentes no Rio de Janeiro. Cad Saúde Pública 2004; 20(Supl 1):283-290.

8. Borges ALV, Schor N. Homens adolescentes e vida sexual: heterogeneidades nas motivações que cercam a iniciação sexual. Cad Saúde Pública 2007; 23(Supl 1):225-234 
9. Aquino $E M L$, Heilborn $M L$, Knauth $D$, Bozon $M$, Almeida MC, Araújo J, M enezes G. Adolescência e reprodução no Brasil: a heterogeneidade dos perfis sociais. Cad Saúde Pública 2003; 19(Supl 20):377-388.

10. Carvalho M LO, Pirotta KCM, Schor N. Participação masculina na contracepção pela ótica feminina. Rev. Saúde Pública 2001; 35(Supl 1):23-31.

11. Gomes R, M endonça EA. A representação e a experiência da doença: princípios para a pesquisa qualitativa em saúde. In. Minayo MCS, Deslandes SF, organizadoras. Caminhos do pensamento: epistemologia e método. Rio de Janeiro: Fiocruz; 2002. p. 109-132.

12. Gagnon JH. U ma interpretação do desejo: ensaios sobre 0 estudo da sexualidade. Rio de Janeiro: Garamond; 2006.

13. Gomes R. Sexualidade masculina e saúde do homem : proposta para uma discussão. Cien Saude Colet 2003: 8(Supl 3):825-829.

14. Abramovy M, Castro M G, Silva LB. Juventude e sexualidade. Brasília: Unesco Brasil; 2004.

15. Ferraz EA, Souza CT, Silva CFR, Costa N. Iniciação sexual de jovens: análise de variáveis a partir de gênero. In: Anais do XV Encontro $\mathrm{Nacional}$ de Estudos Populacionais. 2006; Caxambu. Disponível em: http:/ /www.abep.nepo.unicamp.br

16. Bozon M, Heilborn MA. As carícias e as palavras, iniciação sexual no Rio de Janeiro e em Paris. Novos Estudos Cebrap 2001; 59:111-135.

17. Heilborn ML. Família e sexualidade: novas configurações. In. Heilborn ML. Família e sexualidade. Rio e Janeiro: FGV; 2004. p. 9-14.

18. Leal $A F, K$ nauth $D R$. A relação sexual como uma técnica corporal: representações masculinas dos relacionamentos afetivo-sexuais. Cad Saúde Pública 2006; 22(Supl 7):1375-1384.

19. Bozon M, Giami A. Les scripts sexuels ou la mise em forme du désir - presentation de I article de John Gagnon. Actes de la Recherche em Sciences Sociales 1999; 128.

20. Simon W, Gagnon JH. Sexual Scripts. In: Parker R, Aggleton P, editors. Culture, Society and Sexuality: A Reader. London: UCL PRESS; 1999. p. 29-38.

21. Barker G, Acosta F. Homens, violência de gênero e saúde sexual reprodutiva. [site na Internet]. 2003 [acessado 2006 set 21]. Disponível em: http://promundo.org.br

22. Barker G. AIDS: 0 que os homens te a ver com isso? [site na Internet]. 2003 [ acessado 2006 ago 8]. Disponível em: http://promundo.org.br

23. Schraiber LB, Gomes R, Couto MT. Homens na pauta da saúde coletiva. Cien Saude Colet 2005; 10 (Supl 1):7-17.

24. Deslandes SF, Gomes R. A pesquisa qualitativa em serviços de saúde: notas teóricas. In: Bosi MLM, Mercado FJ, organizadores. Pesquisa qualitativa de serviços de saúde. Petrópolis: Vozes; 2004. p. 99-120.

25. M inayo MCS. Desafio do conhecimento: pesquisa qualitativa em Saúde. 9a ed. São Paulo: Hucitec; Rio de Janeiro: Abrasco; 2006.
26. Jovchelovitch S, Bauer M W. Entrevista narrativa. In: Bauer MW, Gaskell G, organizadores. Pesquisa qualitativa com texto, imagem e som. U m manual prático. Petrópolis: Vozes; 2002. p. 90-113.

27. Vaitsman J. Flexíveis e plurais. Identidade, casamento e família em circunstâncias pós-modernas. Rio de Janeiro: Rocco; 1994.

28. Boghossian CO. Vivências de violência em Vigário Geral: experiência de gerações [dissertação]. Rio de Janeiro: Escola Nacional de Saúde Pública, Fundação Oswaldo Cruz; 1999.

29. Carrano PCR. Juventudes e cidades educadoras. Petrópolis: Vozes; 2003.

30. Neri M . 0 retorno da educação. [site na Internet]. [acessado 2005 dez 18]. Disponível em: http://www.fgv.br/ cps

31. Fernández-Galiano L. Anos 90. [site na Internet]. 1999 [acessado 2006 ago 8]. Disponível em: http:// www.arcoweb.com.br/debate/debate7.asp

32. Brasil. M inistério da Saúde. Aids vinte anos: esboço histórico para entender o Programa Brasileiro. [site na Internet]. [acessado em 2006 ago 5]. Disponível em: http://www.sistemas.aids.gov.br

33. Rosistolato RPR. 0 projeto Aids: classificações de gênero, adolescência e sexualidade em uma escola. [site na Internet]. 2003 [acessado em 2006 set 22]. Disponível em: http://www.enfoques.ifcs.ufrj.br

34. Heilborn ML, Aquino EML, Bozon M, Knauth DR, organizadores. $O$ aprendizado da sexualidade: reprodução e trajetórias sociais de jovens brasileiros. Rio de Janeiro: Garamond/Fiocruz; 2006.

35. Castro M G, Silva LB. Respostas aos desafios da AIDS no Brasil: limites e possibilidades. Brasília: Unesco/ Ministério da Saúde; 2005.

36. Costa RG. Saúde e masculinidade: reflexões de uma perspectiva de gênero. Rev Brasileira de Estudos de População 2003; 20(Supl 1):79-92.

37. Guerriero I, Ayres JCCM, Herst N. Masculinidade e vulnerabilidade ao HIV de homens heterossexuais, São Paulo, SP. Rev. Saúde Pública 2002; 36(Supl 4):50-60.

38. Unbehaum S, Cavasin S, Silva VN. Juventude e prevenção das DST/Aids. [site na Internet]. 2003 [acessado em 2006 ago 13]. Disponível em: http://www.ecos.org.br/ paginas/projetos/políticas adolescente.htm

39. Heilborn ML. Entre as tramas da sexualidade brasileira. Rev Estudos Feministas 2006; 14 (Supl 1):43-59.

40. Louro GL. A emergência do gênero. In: Louro GL, organizadora. Gênero, sexualidade e educação: uma perspectiva pós-estruturalista. 5a ed. Petrópolis: Vozes; 2003.

Artigo apresentado em 14/02/2007 Aprovado em 22/06/2007 